\title{
Studies in primary hypomagnesaemia: evidence for defective carrier-mediated small intestinal transport of magnesium
}

\author{
P. J. Milla, ${ }^{1}$ P. J. AGgeTt, O. H. WOlfF, AND J. T. HARRIES

\begin{abstract}
From The Hospital for Sick Children, Great Ormond Street, and The Institute of Child Health Guilford Street, London
\end{abstract}

SUMMARY A 4 year old male with primary hypomagnesaemia was studied using balance and steadystate perfusion techniques. Magnesium balance was negative and could be accounted for by increased faecal losses, renal conservation being normal; calcium balance was normal. After oral magnesium therapy magnesium balance became positive. The perfusion studies demonstrated net loss of magnesium into the intestinal lumen when low concentrations ( 1 and $2 \mathrm{mmol} / \mathrm{l})$ of magnesium were perfused in contrast with control subjects; whereas at high concentrations $(10 \mathrm{mmol} / \mathrm{l})$ a net absorption of a magnitude similar to control values was observed. In the control subjects sequential perfusion of increasing concentrations of magnesium demonstrated a curvilinear relationship between rates of absorption and the lower concentrations (1, 2, and $4 \mathrm{mmol} / \mathrm{l})$ with an apparent $\mathrm{Km}$ and $\mathrm{Vmax}$ of $4.5 \mathrm{mmol} / 1$ and $91 \mathrm{nmol} / \mathrm{min} / \mathrm{cm}$ respectively. At the higher concentrations $(6$ and $10 \mathrm{mmol} / \mathrm{l})$ the relationship was linear. These data suggest that two separate transport systems participate in the absorption of magnesium from the proximal small intestine; a carrier-mediated system which saturates at low intraluminal concentrations, and a simple diffusional process. The possibility of the second transport system being a carrier-mediated process with a very much higher $\mathrm{Km}$ cannot be excluded. In primary hypomagnesaemia the results suggest that the primary abnormality is a defect in carrier-mediated transport of magnesium from low intraluminal concentrations of magnesium.

Primary hypomagnesaemia is a rare, genetically- -1 Methods determined disorder which presents in early infancy with convulsions and tetany (Paunier et al., 1965; Friedman et al., 1967). Balance studies suggest that intestinal absorption of magnesium may be the primary abnormality (Paunier et al., 1968; Strømme et al., 1969), but the precise site and nature of the absorptive defect have not been defined. This paper presents studies in a patient with primary hypomagnesaemia and provides evidence that the basic abnormality is a defect in carrier-mediated transport of magnesium by the small intestine. A preliminary report of the data has appeared in abstract form (Milla et al., 1977).

CONTROLS AND PATIENT

The control group consisted of three children aged 3 to 4.5 years who were referred with suspected malabsorption and in whom, after extensive negative investigations, a diagnosis of 'irritable bowel syndrome' was made. The balance and perfusion studies in the patient were performed when he was 4 years old. The protocols were approved by the Standing Committee on Ethical Practice of the Hospital for Sick Children, Great Ormond Street, London, and informed consent was obtained from the parents.

INTESTINAL PERFUSION

The patient's oral magnesium therapy was discontinued 24 hours before perfusion.

After an overnight fast, the patient and controls were sedated with intramuscular chlorpromazine $(1.5 \mathrm{mg} / \mathrm{kg})$ one hour before perfusion. The subjects were intubated with a double lumen tube (inlet tube

\footnotetext{
${ }^{1}$ Address for reprints: Dr P. J. Milla, Department of Child Health, Institute of Child Health, 30 Guilford Street, London WC1N $1 \mathrm{EH}$.
}

Received for publication 18 July 1979 
radio-opaque $1.5 \mathrm{~mm}$ internal diameter, Portex $800 / 023 / 200$; outlet tube radiolucent $2.0 \mathrm{~mm}$ internal diameter, Portex 800/010/150); with a proximal and distal orifice $20 \mathrm{~cm}$ apart, and weighted with a distal mercury bag. Under fluoroscopic control the proximal orifice was positioned at the ligament of Treitz. The solutions were perfused at a constant rate $(8.8 \mathrm{ml} / \mathrm{min})$ with a Harvard pump (No. 975) and, after an equilibration period of 30 minutes, the effluent solutions were collected on ice for an additional 30 minutes in 10 minute aliquots. The equilibration period had been previously validated to achieve a 'steady state' by showing that the concentrations of polyethylene glycol (PEG) in effluent collections remained constant. The solutions were perfused sequentially with respect to the concentration of magnesium chloride $\left(\mathrm{MgCl}_{2}\right)$, starting with the lowest concentrations and a 30 minute equilibration period being allowed between each concentration of $\mathrm{MgCl}_{2}$ perfused.

TEST SOLUTIONS

All solutions contained PEG $4000(3 \mathrm{~g} / \mathrm{l}) \mathrm{KCl}$ (4 mmol/l), $\mathrm{NaHCO}_{3}(25 \mathrm{mmol} / \mathrm{l})$, fructose (20 $\mathrm{mmol} / \mathrm{l})$, and their osmolalities were adjusted to $285-290 \mathrm{mOsm} / \mathrm{kg}$ by the addition of $\mathrm{NaCl} ; \mathrm{pH}$ was adjusted to 7.0 by gassing with $\mathrm{CO}_{2} . \mathrm{MgCl}_{2}$ was added in concentrations of $1,2,4,6$, or $10 \mathrm{mmol} / \mathrm{l}$. Fructose was added as an internal control in preference to glucose, as glucose may impair absorption of magnesium (Aldor and Moore, 1970). The constituents of the perfusion solutions were purchased from British Drug Houses.

\section{BALANCE STUDIES}

Three-day magnesium and calcium balance studies were performed by a modification of the method of Alexander et al. (1973).

Urine and faeces were collected using specially cleaned urinals and potties. A carmine marker was given at the start of the balance and an Edicol Blue marker (ICI) exactly 72 hours later. The faecal collection included the carmine but not the blue marker.

Exact duplicate diets were collected for analysis. Food prepared in the hospital diet kitchen was divided into halves. One half was offered to the child and the other stored in deionized polythene containers. Any food not consumed was similarly stored, and drinks were handled in the same way. The difference between the mineral content of the rejected diet and that of the duplicate diet was taken to represent the dietary mineral intake.

The total three-day diet, faecal and urine collections were homogenised using a nylon-coated homogeniser. Weighed portions of these homogenates were transferred to quartz beakers and dried on a sand bath at $100^{\circ} \mathrm{C}$. The samples were then ashed in a muffle furnace for 16 hours at $450^{\circ} \mathrm{C}$. The residues were dissolved in concentrated hydrochloric acid and made up to a known volume for analysis. The concentrations of calcium and magnesium were measured after dilution in $0.1 \%$ lanthanum chloride by atomic absorption spectroscopy (Perkin-Elmer, 1973).

Total intake, urine and faecal excretion and overall balance are expressed in $\mathrm{mmol} / \mathrm{day}$. Control data are taken from an earlier departmental study by Alexander et al. (1973).

\section{ANALYSIS}

Samples were analysed for PEG, and fructose according to previously described methods (Roe et al., 1949; Hydén, 1955). Stool losses of ${ }^{51} \mathrm{Cr}$ were determined after intravenous ${ }^{51} \mathrm{CrCl}_{2}$-tagged albumin (Waldmann, 1961). Magnesium and calcium concentrations were determined as above. Parathormone was assayed by radioimmunoassay using a bovine standard and antiserum (Fairney et al., 1973).

\section{CALCULATIONS}

Rates of absorption or secretion of magnesium in the $20 \mathrm{~cm}$ test segment of jejunum were calculated according to standard formulae (Sladen and Dawson, 1969). In the patient, results are expressed as the mean of the three 10-minute aliquot fractions. In the controls, this mean value is presented together with the range for the three subjects studied.

\section{Case report}

The patient is the first male child of healthy unrelated parents, pregnancy was uneventful, and he was born at term weighing $3.6 \mathrm{~kg}$; he was breast-fed until the age of 13 weeks.

Between the age of 3 and 12 weeks he had several generalised convulsions, at 12 weeks he developed loose stools and peripheral oedema, and was referred to the Hospital for Sick Children.

Physical examination revealed a pale, unresponsive infant whose weight $(6 \cdot 3 \mathrm{~kg})$, height $(64 \mathrm{~cm})$, and head circumference $(47 \mathrm{~cm})$ were on the 75th and 90th, and over the 97th percentile respectively. The anterior fontanelle was tense and bulging, muscle tone was increased, the Chvostek test was positive, and convulsions were frequent and generalised. Clinical examination was otherwise normal.

\section{INITIAL INVESTIGATIONS AND MANAGEMENT Investigations}

Haemoglobin, total and differential white blood count, serum electrolytes, blood urea, liver function 
tests, total serum bilirubin, alanine and aspartate transaminases, alkaline phosphatase, and 5-nucleotidase, urine microscopy and culture, and faecal fat and nitrogen excretion were normal, as was xylose absorption. Plasma magnesium concentration was markedly reduced at $\mathbf{0 . 0 8 4} \mathrm{mmol} / \mathbf{l}$ (normal 0.70 0.93 ); plasma calcium was also reduced at 1.73 $\mathrm{mmol} / \mathrm{l}$ (normal 2.13-2.62), whereas plasma phosphate was increased at $2.78 \mathrm{mmol} / 1$ (normal 1.29 1.78). Total plasma proteins were $41 \mathrm{~g} / 1$ (normal 52-78), and the albumin concentration was $26 \mathrm{~g} / \mathrm{l}$ (normal 36-51 g/l). Plasma parathormone was $105 \mathrm{ng} / \mathrm{l}$ (normal 120-380) and repeat observations demonstrated levels of $<40,50$ and $55 \mathrm{ng} / 1$. Twentyfour hour urinary excretion of magnesium, calcium and phosphate were $0.5,1.11$, and $3.95 \mathrm{mmol}$ respectively, normal ranges being $0 \cdot 20-1 \cdot 10,0 \cdot 05$ 0.98 , and $1.80-4.95 \mathrm{mmol}$ respectively. A proteinlosing enteropathy was demonstrated after intravenous ${ }^{51}$ chromium chloride, $11.6 \%$ of the administered dose being excreted in the stools over a five-day collection period (normal 1-2\%). Peroral small intestinal biopsy was histologically normal under light microscopy. Electroencephalographic studies showed a severe diffuse abnormality, and radioprints of the skull showed marked widening of the sutures.

\section{Management}

Intramuscular magnesium sulphate $(0.4 \mathrm{mmol} / \mathrm{kg} /$ day), oral calcium gluconate $(13.4 \mathrm{mmol} / \mathrm{kg} /$ day $)$, calciferol (40,000 units daily), phenobarbitone $(15 \mathrm{mg} / \mathrm{kg} /$ day $)$, and phenytoin $(7.5 \mathrm{mg} / \mathrm{kg} /$ day $)$ rapidly controlled the fits. His general condition gradually improved.

On this regime plasma calcium returned to normal levels over a period of two weeks, but plasma mag- nesium levels varied from $0.2 \mathrm{mmol} / 1$ to a peak of $0.96 \mathrm{mmol} / \mathrm{l}$. The calcium gluconate, calciferol, and phenytoin were then discontinued without incident, and oral magnesium glycerophosphate $(2 \mathrm{mmol} / \mathrm{kg} /$ day) was substituted for the intramuscular preparation. The oedema resolved and a repeat ${ }^{51}$ chromium chloride test demonstrated a marked reduction in stool excretion (3\% over a five-day collection period); plasma magnesium levels, however, remained low $(0.50-0.60 \mathrm{mmol} / \mathrm{l})$. At the age of 4 months, balance studies were performed which have been previously reported (Smales, 1973) and showed that the patient had a net intestinal loss of magnesium. After these studies oral magnesium chloride therapy $(2.5 \mathrm{mmol} / \mathrm{kg} /$ day $)$ was started; the diarrhoea decreased to three loose stools per day and the rate of head growth returned to normal.

Subsequent progress Figure 1 shows the patient's progress up to the age of 4 years. Progressive increments in the dose of magnesium were required to maintain plasma levels at just below normal. Concomitant with the increasing dose of magnesium, the number of loose stools increased. At the age of 4 years, the dose of magnesium chloride was 3.5 $\mathrm{mmol} / \mathrm{kg} / \mathrm{day}$, the plasma magnesium level was just within the normal range, and his plasma parathormone of $260 \mathrm{ng} / \mathrm{l}$ was normal. He was passing five watery stools per day. His serum proteins (total protein $68 \mathrm{~g} / 1$, albumin $42 \mathrm{~g} / \mathrm{l}$ ) were normal, the height was on the 25th centile, the weight was on the 50th centile, and IQ was 96 on the Stanford Binet Scale.

\section{Balance studies}

Magnesium and calcium balance studies were performed 48 hours after terminating magnesium therapy $(3.5 \mathrm{mmol} / \mathrm{kg} /$ day $)$ and again seven days

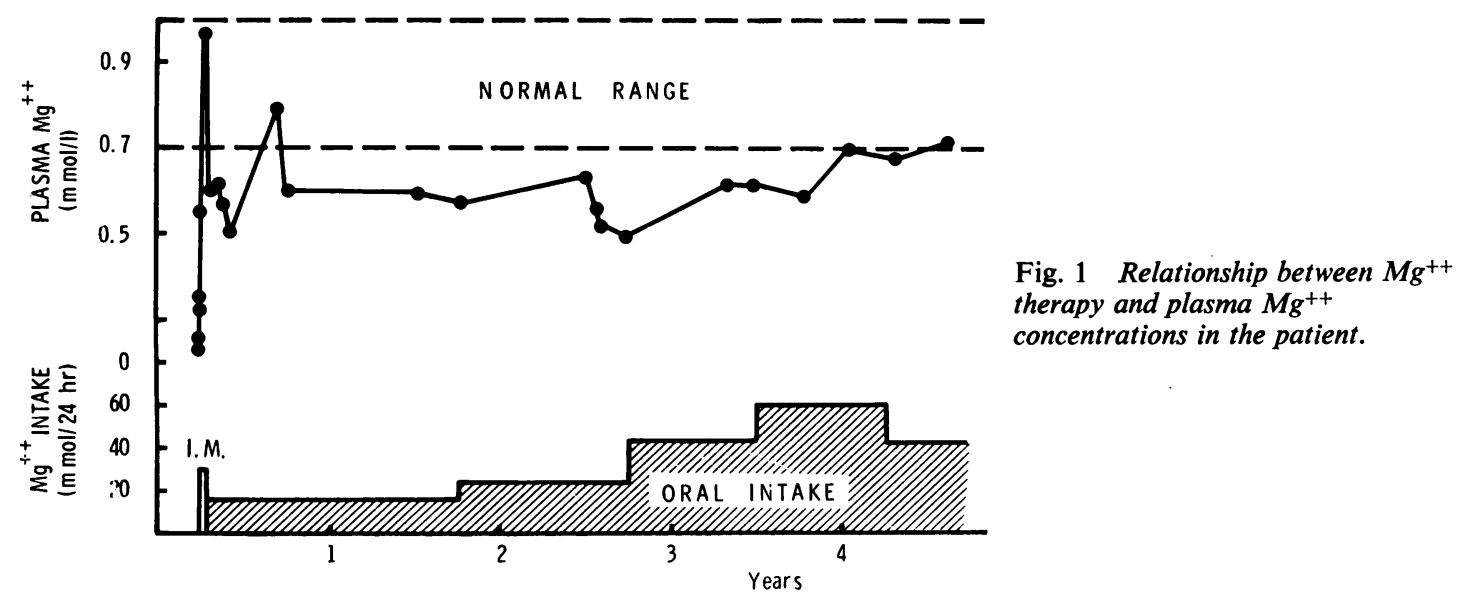



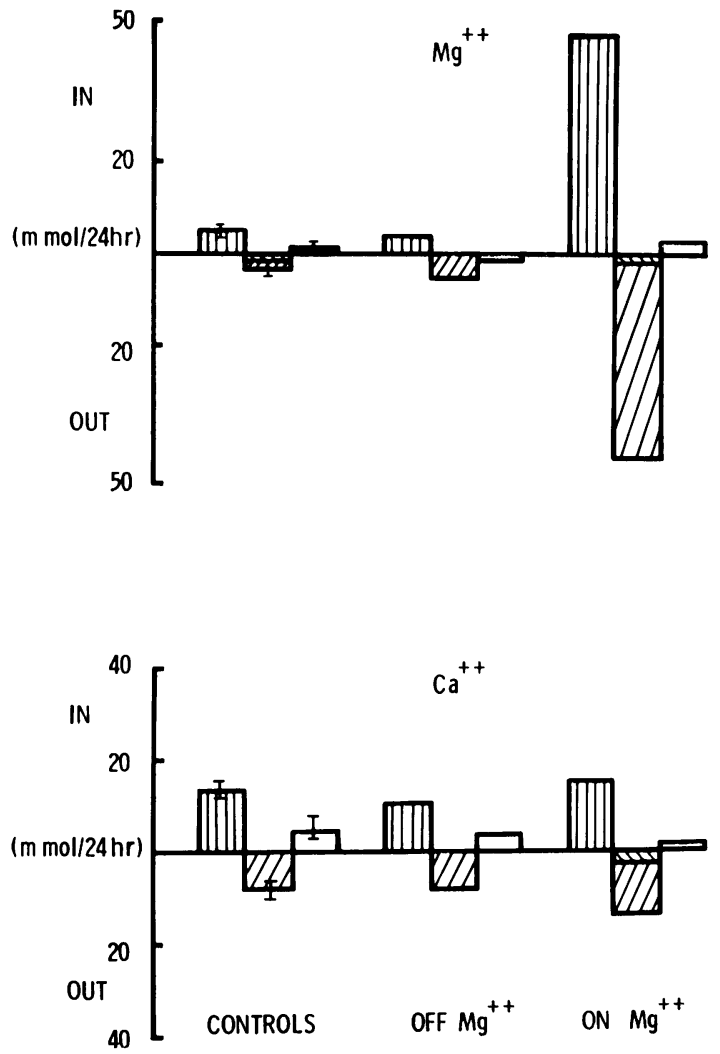

Fig. 2 Three-day $\mathrm{Mg}^{++}$and $\mathrm{Ca}^{++}$balance studies in the patient (aged 4 years) and controls. Histograms denote means $\pm 1 S E$. II) Dietary intake.

$\mathbb{Z}$ Stool output. Urine output. $\square$ Net balance.

after reinstituting magnesium therapy. The results are shown in Fig. 2 together with control data from children, matched for age, on normal diets.

During the first balance period the patient was in negative balance, with respect to magnesium and in positive balance with respect to calcium. The negative magnesium balance was due to excessive stool losses of magnesium, renal conservation being normal; during the balance period plasma magnesium concentrations fell from 0.46 to $0.34 \mathrm{mmol} / \mathrm{l}$.

During the second period, the patient was in a small positive magnesium balance. Faecal excretion of magnesium was again high, but, expressed as a percentage of ingested magnesium, had fallen to $80 \%$. During this balance period the plasma magnesium concentration rose from 0.51 to 0.72 $\mathrm{mmol} / \mathrm{l}$.

\section{Perfusion studies}

$\mathrm{Th}$ ? results are shown in Fig. 3 and the Table.
The three children serving as controls were sequentially perfused with $1,2,4,6$, and $10 \mathrm{mmol} / \mathrm{l}$ magnesium chloride. The relationship between the magnesium concentration on the perfusate and the net rate of magnesium absorption is presented as a Lineweaver Burke plot in Fig. 3. At low concentrations of perfused magnesium the line is curved and at higher concentrations straight. The Lineweaver Burke transformation gives an apparent $\mathrm{Km}$ of $4.5 \mathrm{mmol} / 1$ and a $V \max$ of $91 \mathrm{nmol} / \mathrm{min} / \mathrm{cm}$. The data suggest the presence of two transport systems: a system which saturates at low luminal concentrations of magnesium and a simple diffusional system.

In the patient, in contrast with the control subjects, absorption of magnesium did not occur at the two lower concentrations ( 1 and $2 \mathrm{mmol} / \mathrm{l}$ ) of magnesium chloride perfused (Table). At $10 \mathrm{mmol} / \mathrm{l}$ of magnesium chloride, absorption occurred in both patient and controls at similar mean rates (patient, 115 $\mathrm{nmol} / \mathrm{min} / \mathrm{cm}$; controls, $104 \mathrm{nmol} / \mathrm{min} / \mathrm{cm}$.)

As shown in the Table, there was slight net water absorption at low luminal magnesium concentration in the control subjects; with increasing luminal magnesium concentration net water absorption rates decreased, and, at 6 and $10 \mathrm{mmol} / 1$ magnesium chloride, there was water secretion. Water absorption and secretion rates in the patient were similar to those in the control subjects.

Mean net absorption of fructose was similar in the

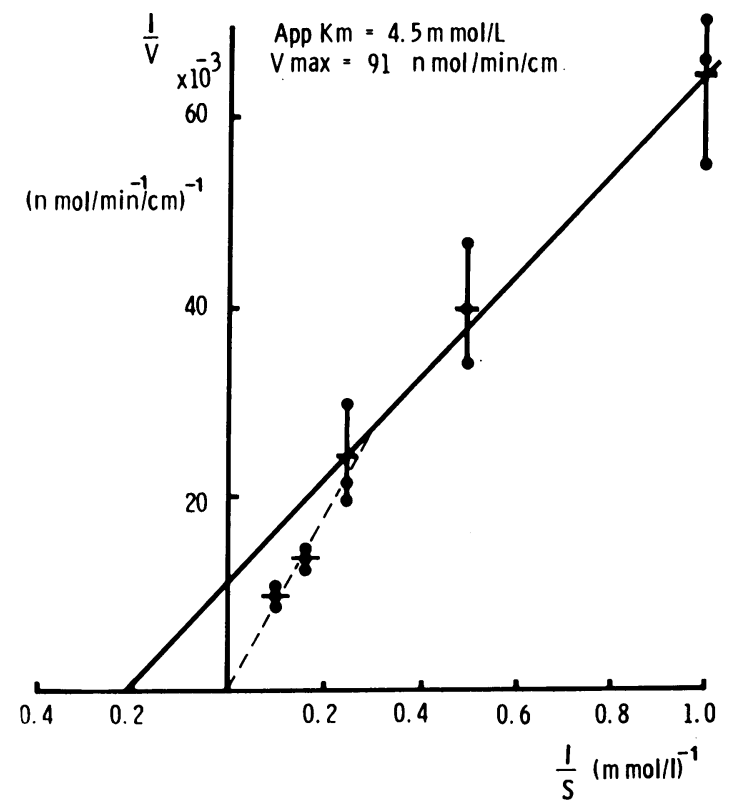

Fig. 3 Lineweaver-Burke plot of $\mathrm{Mg}^{++}$absorption in controls. 
patient and control subjects at $1 \mathrm{mmol} / 1$ magnesium (patient, $1.75 \mu \mathrm{mol} / \mathrm{min} / \mathrm{cm}$; controls $1.67-2.22$ $\mu \mathrm{mol} / \mathrm{min} / \mathrm{cm}$ ); and $2 \mathrm{mmol} / 1$ magnesium (patient, $1.56 \mu \mathrm{mol} / \mathrm{min} / \mathrm{cm}$, controls, $1.54-2.16 \mu \mathrm{mol} / \mathrm{min} /$ $\mathrm{cm}$ ); but at $10 \mathrm{mmol} / 1$ magnesium, fructose absorption in the patient was slightly reduced (patient, $1 \cdot 38$, controls $1 \cdot 75-2 \cdot 63$ ).

\section{Discussion}

Our studies support previous reports based on balance studies that the magnesium deficiency in primary hypomagnesaemia results from malabsorption of magnesium (Paunier et al., 1965; Friedman et al., 1967; Paunier et al., 1968; Strømme et al., 1969; Salet et al., 1966; 1970; Nordio et al., 1971), and suggest, to our knowledge for the first time, that the basic abnormality responsible for the malabsorption is a specific defect in carrier-mediated transport of magnesium.

The results of the perfusion studies suggest that at least two separate systems participate in the absorption of magnesium from the proximal jejunum; a system which saturates at low intraluminal concentrations and thus may be carrier mediated, and a simple diffusional system. Alternatively, there may be two carrier-mediated transport systems with high and low affinity properties. In our patient, the basic defect appears to be an abnormality of the process which is essential for the absorption of magnesium from low intraluminal concentrations. At higher intraluminal concentrations magnesium absorption in our patient was normal, and this finding explains how oral administration of magnesium in primary hypomagnesaemia corrects the magnesium deficiency.
Little information is available regarding the in vivo characteristics of magnesium absorption in man. Brannan et al. (1976), using a steady-state perfusion technique, studied absorption of magnesium and calcium in healthy adult volunteers. Magnesium was equally well-absorbed in the jejunum and ileum and displayed saturation kinetics at both sites. They found that the half-maximal absorption rate was about $5 \mathrm{mmol} / \mathrm{l}$, which is approximately that found in our control subjects $(4.5 \mathrm{mmol} / \mathrm{l})$. Review of their data concerning the jejunum suggests that, as in our control subjects, at least two systems may participate in the absorption of magnesium. Previous reports have suggested that magnesium and calcium share a common transport system (Alcock and MacIntyre, 1960). More recent studies in the human (Brannan et al., 1976) and the experimental animal (O'Donnell and Smith, 1973), however, suggest the existence of discrete and separate transport systems for the two metals. The fact that, in our patient, the balance studies showed abnormal magnesium absorption in the presence of normal absorption of calcium supports these recent findings.

In patients with primary hypomagnesaemia, high doses of oral magnesium supplements are necessary to maintain normal blood levels, and such therapy often leads to troublesome diarrhoea, as occurred in our patient. In this context, it is relevant to note that in our patient and the controls, high (6-10 $\mathrm{mmol} / \mathrm{l})$ but not lower concentrations of perfused magnesium induced net secretion of fluid. Harvey and Read (1973) suggested that the mechanism whereby magnesium induces intestinal secretion of fluid may be through the release of cholecystokinin-

Table Net water and magnesium transport in jejunum of patient and controls

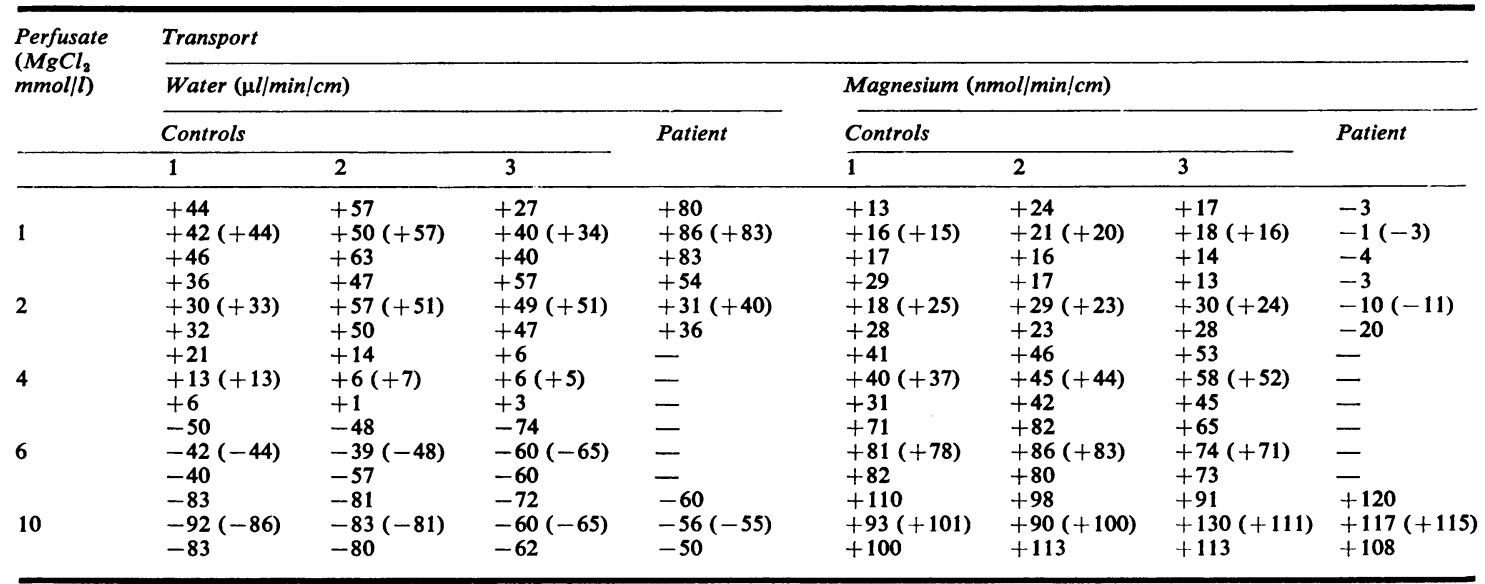

+ net absorption.

- net secretion.

Figures in parentheses denote means of the three 10 minute collection periods. 
pancreozymin. Ploth et al. (1976) showed that magnesium inhibits $\mathrm{Na}$ absorption in the proximal renal tubule of the rat and a similar explanation may apply in the small intestine, which has very similar transport mechanisms.

The relationship between some of the clinical and biochemical abnormalities in our patient has not been fully defined in the present study, but poses a number of interesting possibilities. For example, the fact that the oedema, hypoalbuminaemia, proteinlosing enteropathy, and hydrocephaly improved after magnesium therapy suggests that these abnormalities may have been due to magnesium deficiency.

P. J. M. and P. J. A. gratefully acknowledge the financial support given by the National Fund for Research into Crippling Diseases and the Medical Research Council. We thank Mr J. Mitchell for performing the magnesium and calcium determinations.

\section{References}

Alcock, N., and MacIntyre, I. (1960). Interrelation of calcium and magnesium absorption (Abstract). Biochemical Journal, 76, 19 P.

Aldor, T. A. M., and Moore, E. W. (1970). Magnesium absorption by everted sacs of rat intestine and colon. Gastroenterology, 59, 745-753.

Alexander, F. W., Clayton, B. E., and Delves, H. T. (1973). Mineral and trace-metal balances in children receiving normal and synthetic diets. Quarterly Journal of Medicine, 43, 89-105.

Brannan, P. G., Vergne-Marini, P., and Pak, C. Y. C., Hull, A. R., and Fordtran, J. S. (1976). Magnesium absorption in the human small intestine: Results in normal subjects, patients with chronic renal disease, and patients with absorptive hypercalciuria. Journal of Clinical Investigation, 57, 1412-1418.

Fairney, A., Jackson, D., and Clayton, B. E. (1973). Measurement of serum parathyroid hormone, with reference to some infants with hypocalcaemia. Archives of Disease in Childhood, 48, 419-424.

Friedman, H., Hatcher, G., and Watson, L. (1967). Primary hypomagnesaemia with secondary hypocalcaemia in an infant. Lancet, 1, 703-705.

Harvey, R. F., and Read, A. E. (1973). Saline purgatives act by releasing cholecystokinin. Lancet, 2, 185-187.

Hydén, S. (1956). A turbidimetric method for the determination of higher polyethylene glycols in biological materials. Kungliga Lantbrukshögskolans annaler, 22, 139-145.
Milla, P. J., Wolff, O. H., and Harries, J. T. (1977). Studies in primary hypomagnesaemia; evidence for a defect in carrier-mediated transport of magnesium (Abstract). Gut, 18, A943.

Nordio, S., Donath, A., Macagno, F., and Gatti, R. (1971). Chronic hypomagnesemia with magnesiumdependent hypocalcemia. I. A new syndrome with intestinal magnesium malabsorption. Acta Paediatrica Scandinavica, 60, 441-455.

O'Donnell, J. M., and Smith, M. W. (1973). Uptake of calcium and magnesium by rat duodenal mucosa analysed by means of competing metals. Journal of Physiology, 229, 733-749.

Paunier, L., Radde, I. C., Kooh, S. W., and Fraser, D. (1965). Primary hypomagnesemia with secondary hypocalcemia. Journal of Pediatrics, 67, 945 (Abst).

Paunier, L., Radde, I. C., Kooh, S. W., Cohen, P. E., and Fraser, D. (1968). Primary hypomagnesemia with secondary hypocalcemia in an infant. Pediatrics, 41, $385-402$.

Perkin-Elmer 'Cookbook'. (1973). Analysis of serumdetermination of $\mathrm{Ca}, \mathrm{Mg}, \mathrm{Na}, \mathrm{K}$. Page Ref. BC1-R. Perkin-Elmer Corpn. Inc., Norwalk, Connecticut.

Ploth, D. W., Sawin, L. L., and Dibona, G. F. (1976). Effect of magnesium on rat nephron sodium reabsorption. A segmental analysis. American Journal of Physiology, 230, 398-402.

Roe, J. H., Epstein, J. H., and Goldstein, N. P. (1949). A photometric method for the determination of inulin in plasma and urine. Journal of Eiological Chemistry, 178, 839-845.

Salet, J., Polonovki, C., de Gouyon, F., Pean, G., Melekian, B., Fournet, J. P., Aymard, P., Raynaud, C., Vincent, J. (1966). Tétanie hypocalcémique récidivante par hypomagnésémie congénitale: une maladie métabolique nouvelle. Archives Francaises de Pédiatrie, 23, 749-768.

Salet, J., Polonovki, C., Fournet, J. P., de Gouyon, F., Aymard, P., Pean, G., and Taillemite, J. L. (1970). Démonstration de la nature familiale de l'hypomagnésémie congénitale chronique (Abstract). Archives Françaises de Pédiatrie, 27, 550-551.

Sladen, G. E., and Dawson, A. M. (1969). Interrelationships between the absorptions of glucose, sodium and water by the normal human jejunum. Clinical Science, 36, 119-132.

Smales, O. R. C. (1973). Primary infantile hypomagnesaemia. Proceedings of the Koyal Society of Medicine, 67, 759-760.

Strømme, J. H., Nesbakken, R., Normann, T., Skjørten, F., Skyberg, D., and Johannessen, B. (1969). Familial hypomagnesemia. Biochemical, histological and hereditary aspects studied in two brothers. Acta Paediatrica Scandinavica, 58, 433-444.

Waldmann, T. A. (1961). Gastrointestinal protein loss demonstrated by $\mathrm{Cr}^{51}$ albumin. Lancet, 2, 121-123. 